\title{
Current nutritional status of patients with rheumatic diseases in the population of Poland
}

\author{
Anna Kłak ${ }^{1,2}$, Jacek Borowicz², Małgorzata Mańczak², Jolanta Grygielska², Piotr Samel-Kowalik², \\ Filip Raciborski ${ }^{1,2}$
}

${ }^{1}$ Department of Prevention of Environmental Hazards and Allergology, Medical University of Warsaw, Poland

${ }^{2}$ Department of Epidemiology and Health Promotion, Institute of Rheumatology, Warsaw, Poland

\begin{abstract}
The aim of the study was to evaluate the current state of nutrition of patients with rheumatic diseases in the Polish population.

Material and methods: An anonymous questionnaire study was carried out among the patients of the Institute of Rheumatology in Warsaw in the fourth quarter of 2012. Five hundred questionnaires were distributed, and 397 questionnaires were collected and accepted for further analysis (response rate $=79 \%)$.

Results: Overweight or obesity was present in more than half $(53 \%)$ of the patients (overweight in $30.5 \%$ of respondents, obesity in $22.6 \%$ ). Among obese subjects, $43 \%$ of men and $37 \%$ of women in the study think that their diet is correct. Sixty-eight percent of respondents declared that they do not follow any special diet and only $18 \%$ declared that they follow a diet with a reduced quantity of monosaccharides (no sweets). A milk-free diet was followed by $7 \%$ of respondents, a meat-free diet by $6 \%$, and a fruit-and-vegetable diet by $5 \%$. Dietary supplements were regularly used by $26.7 \%$ of respondents, whereas 33.8\% did not use them at all. The average assessment of physical aptitude (Health Assessment Questionnaire - HAQ) in the group of respondents was 0.71. No statistically significant differences were found between higher level of disability (e.g. $\mathrm{HAQ} \geq 1$ ) and the type of diet followed $(p=0.678)$ or body mass index $(\mathrm{BMI})$ value $(p=0.864)$ in relation to persons with the value of $\mathrm{HAQ}<1$. Conclusions: More than half of patients suffering from rheumatic diseases are overweight or obese, which corresponds to the body weight profile of the population of Poland. Most patients diagnosed with rheumatic diseases do not follow any special diet. In spite of the frequent use of dietary supplements, the patients do not consult a doctor or a dietician about it. The type of diet and BMI value do not differ according to the level of disability.
\end{abstract}

Key words: rheumatic diseases, diet, dietary supplements, HAQ.

\section{Introduction}

Rheumatic disorders are progressive conditions that reduce the quality of life of the patient. The most common inflammatory rheumatic disorders include rheumatoid arthritis, spondyloarthropathies and osteoarthritis. Connective tissue diseases such as systemic lupus erythematosus, Sjögren's syndrome, scleroderma or dermatomyositis occur less often [1-11].
Rheumatoid arthritis (RA) is an autoimmune, progressive, systemic disease of connective tissue. It is characterized by non-specific inflammation of the joints (symmetrical in most cases), the occurrence of extra-articular changes as well as systemic complications. The disease leads to disability, and premature death [1]. The prevalence of RA in highly developed countries ranges from 0.5 to $1.0 \%$ [2]. There are no direct data for Poland. It is estimated that the prevalence of rheuma- 
toid arthritis in Eastern Europe in men is 0.14\% (95\% $\mathrm{Cl}$ : $0.08-0.22 \%)$ and in women $0.38 \%(95 \% \mathrm{Cl}$ : 0.24 $0.57 \%)$. In Central Europe the prevalence of rheumatoid arthritis is $0.15 \%$ in men (95\% Cl: $0.11-0.19 \%)$ and $0.41 \%$ in women (95\% Cl: $0.31-0.52 \%)$ and for Western Europe $0.24 \%$ (95\% Cl: $0.21-0.28 \%)$ and $0.63 \%(95 \% \mathrm{Cl}: 0.55-$ $0.75 \%)$ respectively [3].

Spondyloarthropathies (SpA) are an interconnected group of rheumatic disorders, characterized by common clinical symptoms and a similarity of genetic conditions. Spondyloarthropathies include, among others, ankylosing spondylitis (AS) and psoriatic arthritis (PsA) [4]. The disease affects more often men than women (in $2: 1$ proportion). Usually the prevalence is from $0.1 \%$ to $1.4 \%$ worldwide [5], although even more significant estimations can be met in the world (0.036-0.10\%) [6].

Systemic lupus erythematosus (SLE) is a rare, chronic, inflammatory disease of autoimmune origin. Its etiology is multifactorial, and clinical symptoms are varied and depend on simultaneous occupation of many tissues and organs. The symptoms of SLE are most often dermatological, musculoskeletal, renal and cytopenic [7]. In Northern Europe the prevalence is assessed at 40 cases per 100000 persons, and in the case of African-American persons at 200 per 100000 persons. In the world population SLE is most commonly found in women: 80-90\% of patients suffering from SLE are women [8]. The peak incidence of SLE falls at the relatively young age of 20 to 40 years (average 29 years) [8, 9].

Osteoarthritis (OA) is a group of overlapping disorders that in spite of aetiological differences lead to similar health consequences [10]. It is estimated that at a whole life level the risk of occurrence of osteoarthritis of e.g. the knee is almost 45\% [6].

Rheumatic disorders require appropriate and suitable nutrition of patients, the aim of which is to strengthen the therapeutic process. Because of the diversity of rheumatic disorders the persons suffering from inflammatory disorders (such as RA or PsA) should follow a different diet than persons suffering from $O A$. The diet should reduce inflammatory reaction and the pain [11-14]. Studies have confirmed that rheumatic disorders are less frequent and progress more mildly in Southern Europe, which may suggest that the Mediterranean diet (rich in fish, olive oil and cooked vegetables) influences the diseases' course even though the impact of this influence is limited [11]. It is assumed that the consumption of large quantities of fish, olive oil and cooked vegetables can reduce the risk of the disease. This effect is connected with the high level of omega-3 acids [12]. The positive effect has also been noted for vitamin D and K [14]. The increased intake of table salt (sodium chloride) is also a significant factor that influences the development of autoimmune diseases, including RA. Excess salt in the diet can lead to stimulation of Th17 cells and cause up to a 10-fold increase in their number, therefore inducing inflammation [13].

The aim of this study was to assess the diet and its influence on the quality of life of patients suffering from rheumatic disorders.

\section{Material and methods}

An anonymous questionnaire survey was carried out among the patients of the Institute of Rheumatology in Warsaw (IR) from September to December 2012. The survey was distributed in the outpatient clinic as well as hospital wards of the institute. The respondents individually filled in the forms and then placed them in the prepared boxes.

The questionnaire was composed of 25 questions, including anthropometric questions. Apart from the demographics it included questions on the use of dietary supplements, the method of nutrition and its evaluation, consulting a doctor or dietician about the diet, the evaluation of health status, the occurrence of symptoms of a rheumatic disorder, comorbidities, quality of life, and fitness determination (Health Assessment Questionnaire-HAQ). The HAQ includes questions on the degree of independence when performing the following activities: dressing and grooming, arising, eating, walking, hygiene, reach, grip, and activities. Data on weight and height measurements were obtained from the declaration of the respondents. The statistical analysis was performed using the following tests: odds ratio (OR), $\chi^{2}$, Kruskal-Wallis analysis. The differences with $p<0.05$ were considered as statistically significant.

Five hundred questionnaires were distributed during the study, and 397 questionnaires were collected and accepted for further analysis (response rate $=79 \%$ ). The characteristics of the study group are presented in Table I.

\section{Results \\ Obesity and overweight}

The survey results show that more than half (53\%) of the institute's patients suffer from overweight or obesity (overweight $-30.5 \%$, obesity $-22.6 \%$ ). These conditions affect $56 \%$ of men and $52 \%$ of women. In the group of women obesity was found in $24 \%$ of patients and overweight in $28 \%$, and in men $18 \%$ and $38 \%$, respectively. Among overweight men $80 \%$ considered their nutrition as appropriate. Among women this percentage was lower (63\%), but no statistically significant relations between sex groups were determined ( $p=0.73$ ). Over $38 \%$ of respondents who in the study were found 
Table I. Study group characteristics

\begin{tabular}{|c|c|c|}
\hline & $N$ & $\%$ \\
\hline \multicolumn{3}{|l|}{ Gender } \\
\hline female & 307 & 77 \\
\hline male & 90 & 23 \\
\hline total & 397 & 100 \\
\hline \multicolumn{3}{|l|}{ Age } \\
\hline mean & 54.3 & \\
\hline standard deviation & 15.7 & \\
\hline median & 57 & \\
\hline \multicolumn{3}{|c|}{ Time of treatment by rheumatologist } \\
\hline under 1 year & 72 & 18 \\
\hline 2 to 3 years & 49 & 12 \\
\hline $4-5$ & 45 & 11 \\
\hline $6-10$ & 56 & 14 \\
\hline over 10 & 162 & 41 \\
\hline \multicolumn{3}{|c|}{ Reason for treatment by rheumatologist } \\
\hline osteoarthritis & 107 & 27 \\
\hline rheumatoid arthritis & 165 & 42 \\
\hline ankylosing spondylitis & 57 & 14 \\
\hline psoriatic arthritis & 21 & 5 \\
\hline lupus & 8 & 2 \\
\hline other & 63 & 16 \\
\hline \multicolumn{3}{|l|}{ Comorbidities } \\
\hline hypertension & 140 & 35 \\
\hline coronary artery disease & 46 & 12 \\
\hline diabetes & 22 & 6 \\
\hline food allergies & 15 & 4 \\
\hline osteoporosis & 110 & 28 \\
\hline none of the above & 91 & 23 \\
\hline \multicolumn{3}{|l|}{ Education } \\
\hline university degree & 144 & 36.3 \\
\hline secondary & 141 & 35.5 \\
\hline post-secondary & 34 & 8.6 \\
\hline basic vocational & 51 & 12.8 \\
\hline lower secondary & 3 & 0.8 \\
\hline elementary & 14 & 3.5 \\
\hline \multicolumn{3}{|l|}{ Labour market status } \\
\hline working & 136 & 34 \\
\hline pensioner & 87 & 22 \\
\hline retired & 160 & 40 \\
\hline pupil/student & 19 & 5 \\
\hline \multicolumn{3}{|l|}{$\mathrm{BMI}^{*}$} \\
\hline below the standard & 10 & 2.5 \\
\hline standard & 174 & 44.3 \\
\hline overweight & 120 & 30.5 \\
\hline obese & 89 & 22.6 \\
\hline
\end{tabular}

*standard BMI: 18.5-24.99
Table II. Nutritional habits

\begin{tabular}{|lcc|}
\hline & $N$ & $\%$ \\
\hline \begin{tabular}{lcc|} 
Usually, which of the meals mentioned \\
below do you have during the day?
\end{tabular} & \\
\hline breakfast & 350 & 88 \\
\hline second breakfast & 140 & 35 \\
\hline lunch & 361 & 91 \\
\hline afternoon snack & 98 & 25 \\
\hline dinner & 296 & 75 \\
\hline Do you snack between meals? & & \\
\hline yes, regularly & 39 & 10 \\
\hline yes, occasionally & 266 & 67 \\
\hline no & 88 & 22 \\
\hline Usually you eat the largest meal & & \\
\hline in the morning & 66 & 17 \\
\hline during the day & 263 & 66 \\
\hline in the evening & 60 & 15 \\
\hline How many litres of fluids do you drink per day? & \\
\hline up to 1 litre (up to 4 glasses) & 82 & 20.7 \\
\hline ca. 1.0-1.5 litres (5-6 glasses) & 157 & 39.5 \\
\hline ca. 1.5-2 litres (7-8 glasses) & 112 & 28.2 \\
\hline 2 litres or more (over 8 glasses) & 44 & 11.1 \\
\hline
\end{tabular}

to be overweight thought that they were eating well ( $p=0.642$ ), and $47 \%$ of respondents were of a different opinion. There was no significant difference in the results according to gender.

\section{Nutritional habits}

Over $75 \%$ of respondents had 3 main meals during the day (breakfast, lunch and dinner). Every fourth person had an afternoon snack, and every third had a "second breakfast". Four out of five respondents declared that they snacked between meals. In most cases the respondents had the largest meal during the day. Over 39\% of respondents drank from 5 to 6 glasses of fluids per day (Table II).

\section{Diet}

The majority (68\%) of respondents declared that do not follow any special diet. Only $18 \%$ indicated that they follow a diet with reduced quantities of monosaccharides (no sweets), $7 \%$ of respondents follow a milk-free diet, $6 \%$ a meat-free diet and 5\% a fruit-and-vegetable diet. Gender had no statistically significant effect on the results $(p>0.05)$. In the group of patients diagnosed with inflammatory diseases HAQ index had the lowest values for the patients following a vegan and milk-free diet, compared to patients who followed other diets 
Table III. Range of Health Assessment Questionnaire (HAQ) index in relation to the diet, with allocation to inflammatory and non-inflammatory diseases

\begin{tabular}{|c|c|c|c|c|c|c|c|c|c|c|c|c|}
\hline \multirow[t]{3}{*}{ Type of diet } & \multicolumn{12}{|c|}{$\mathrm{HAQ}^{*}$} \\
\hline & \multicolumn{4}{|c|}{ Total ( $N=396$ persons $)$} & \multicolumn{4}{|c|}{ Inflammatory diseases^ } & \multicolumn{4}{|c|}{ Osteoarthritis } \\
\hline & $\begin{array}{c}N \\
(\%)\end{array}$ & $\begin{array}{l}\text { Me- } \\
\text { dian }\end{array}$ & $\mathrm{IQR}^{\#}$ & $\begin{array}{l}\text { Value } \\
\min - \\
\max \end{array}$ & $N$ & $\begin{array}{l}\text { Me- } \\
\text { dian }\end{array}$ & $I_{Q} R^{\#}$ & $\begin{array}{l}\text { Value } \\
\min - \\
\max \end{array}$ & $N$ & $\begin{array}{l}\text { Me- } \\
\text { dian }\end{array}$ & $I_{Q} R^{\#}$ & $\begin{array}{c}\text { Value } \\
\min - \\
\max \end{array}$ \\
\hline $\begin{array}{l}\text { meat-free } \\
\text { (vegetarian) }\end{array}$ & $25(6 \%)$ & 0.55 & $0.2-1.0$ & $0-1.8$ & 11 & 0.60 & $0.10-1.25$ & $0-1.80$ & 3 & $* * *$ & *** & *** \\
\hline $\begin{array}{l}\text { fruit-and-vegetable } \\
\text { (vegan) })^{\star \star}\end{array}$ & $19(5 \%)$ & 0.5 & $0.27-0.90$ & $0-1.05$ & 11 & 0.55 & $0.30-0.95$ & $0-1.05$ & 2 & $* * \star$ & $\star \star \star *$ & 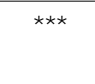 \\
\hline milk-free & $29(7 \%)$ & 0.5 & $0.33-1.05$ & $0-2.0$ & 11 & 0.50 & $0.35-1.05$ & $0.15-1.70$ & 2 & $* * *$ & *** & *** \\
\hline $\begin{array}{l}\text { with reduced } \\
\text { monosaccharides } \\
\text { (no sweets) }\end{array}$ & $71(18 \%)$ & 0.65 & $0.3-1.1$ & $0-2.2$ & 26 & 0.60 & $0.28-1.15$ & $0-2.20$ & 10 & 0.33 & $0.16-0.55$ & $0-0.93$ \\
\hline $\begin{array}{l}\text { do not follow } \\
\text { any special }\end{array}$ & $266(68 \%)$ & 0.55 & $0.15-1.06$ & $0-2.8$ & 145 & 0.80 & $0.30-1.25$ & $0-2.80$ & 55 & 0.30 & $0.05-0.65$ & $0-2.22$ \\
\hline
\end{tabular}

${ }^{*} H A Q \geq 1$ - clinical disability, i.e. the occurrence of some degree of limitation in most areas of everyday life. HAQ > 2.25 - high index of disability (Rupiński R, Filipowicz-Sosnowska A. Disease activity and functional disability in rheumatoid arthritis patients. Reumatologia 2005; 43: 129-137).

**Vegan diet means not eating not only meat, but also products the production of which is related to the exploitation of animals, such as dairy products (including eggs) and (usually) honey.

***Too few to carry out statistical analysis.

$\# I Q R$ - interquartile range.

$\wedge R A, P S A, A S, S L E$

(meat-free, with reduced monosaccharides) or no diet at all. However, in this group of patients no statistically significant relationship was found between the value of the HAQ index and the type of diet (Kruskal-Wallis analysis $p=0.674$ ). In the case of OA patients the groups were too small to statistically analyse the HAQ index and the type of diet (Table III).

\section{Use of dietary supplements}

Only $26.7 \%$ of respondents reported regular use of supplements during the last 6 months. Another 36.5\% used them occasionally. The remaining $33.8 \%$ did not use supplements within the indicated period. The supplements most often used were: calcium - by $56 \%$ of respondents; single vitamins (A, B, C, D, E, folic acid) $54 \%$; supplements with fatty acids $-36 \%$; multivitamins $-23 \%$; supplements with glucosamine sulphate and/or chondroitin $-21 \%$; and collagen $-12 \%$. Among the users of supplements, $28 \%$ reported that all the drugs were recommended by a doctor and $36 \%$ that only some of them were. However, $37 \%$ of respondents used dietary supplementation without a doctor's supervision.

\section{Role of diet}

Sixty-four percent of male respondents and $68 \%$ of women reported that the diet influences their rheumatic disorders. However, only $12 \%$ of men and $19 \%$ of women within the study group have consulted a doctor or a dietician about the diet. In $27 \%$ of respondents rheumatic disease caused the change of diet, whereas $69 \%$ of respondents did not change the diet because of a rheumatic disorder. Over $59 \%$ of respondents reported that their diet is correct, whereas nearly $25 \%$ had the opposite opinion.

\section{Influence of consumed products on well-being of the patient}

Figure 1 presents the responses of subjects related to the intake of given groups of products and experiencing rheumatic diseases. Although over $60 \%$ of respondents stated that diet influences their rheumatic disease, in the case of individual food groups, 10-39\% of respondents stated there was such a relationship. Most often the positive influence was assigned to groats (39\% of respondents) and oily fish (32\%). The respondents declared that they felt worse only after the consumption of alcohol (47\%). In the case of other products from 0 to $17 \%$ of respondents declared that they felt worse.

The distribution of responses for the variable "groats" is statistically significantly different from the distribution of responses for the remaining variables, except the variables eggs $(p=0.0973)$ and fish $(p=0.2977)$. 


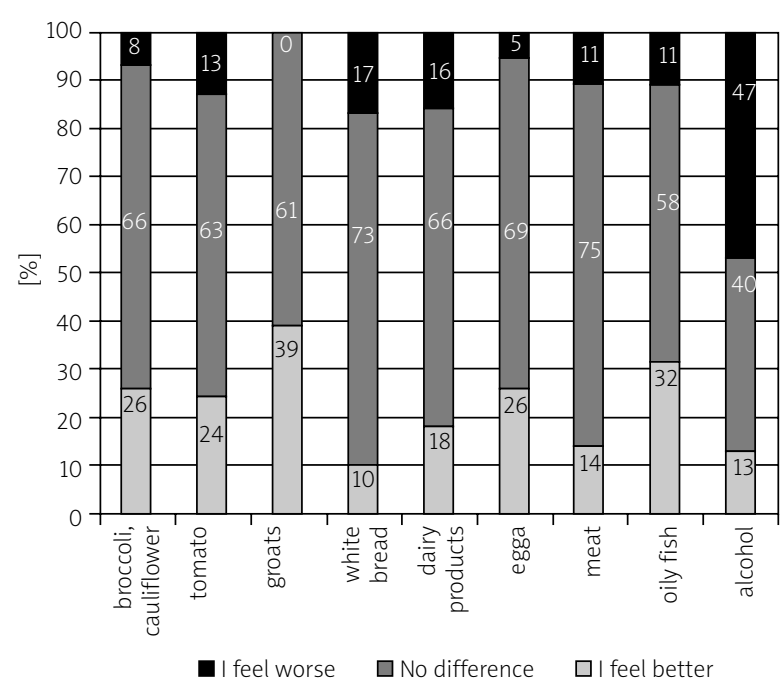

Fig. 1. Distribution of responses to the questions on the influence of selected products on rheumatic diseases.

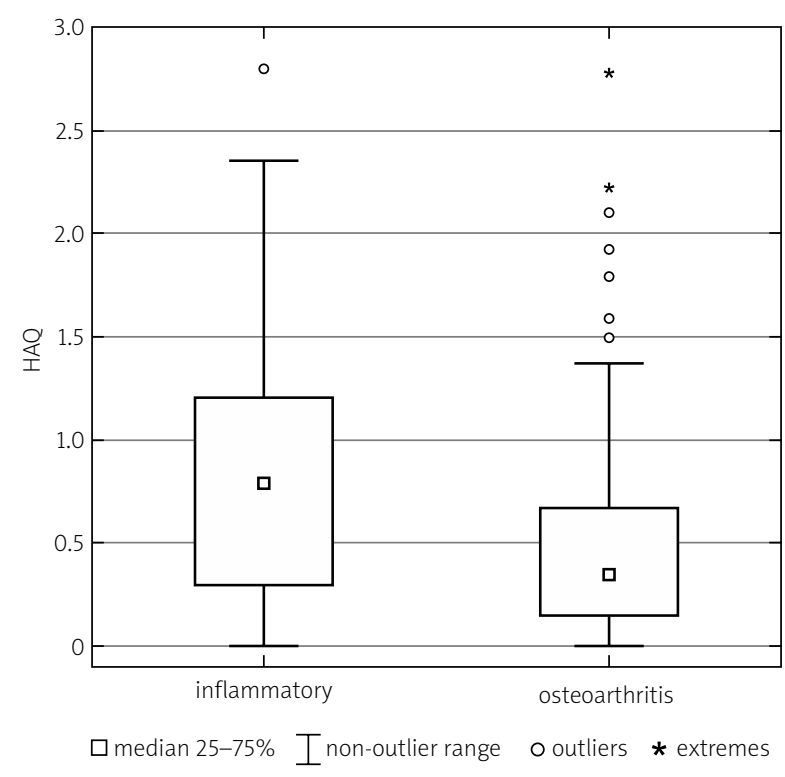

Fig. 2. Health Assessment Questionnaire depending on the diagnosis.

\section{Subjective assessment of health status and Health Assessment Questionnaire}

In response to the question "How do you assess your health status?" $47.9 \%$ of respondents replied "neither good nor bad", $25.2 \%$ of respondents reported their health status as "bad", and 22.2\% as "good". Opposite answers, i.e. "very bad" and "very good", were given by $1 \%$ and $3 \%$ of respondents respectively.

Symptoms such as pain (53.9\%), reduced mobility (30.5\%) and swelling of joints (7.8\%) hamper everyday life of the patients.
The average assessment of fitness ( $\mathrm{HAQ}$, range of evaluation: 0-3) in the study group was 0.71 (standard deviation: 0.62, median: 0.55). In the group of patients with inflammatory diseases the median HAQ index value was 0.79 and in the group of patients with OA it was 0.35 . In the group of patients with inflammatory diseases (RA, AS, PSA, SLE) the value of the HAQ index was statistically significantly higher than in the group of patients with osteoarthritis (Mann-Whitney U-test: $p<0.0001$ ) (Fig. 2).

No statistically significant relationship between higher level of disability (e.g. HAQ $\geq 1$ ) and the type of diet $(p=0.678)$ as well as the value of BMI $(p=0.864)$ was found in relation to persons with the index value of $\mathrm{HAQ}<1$.

\section{Discussion}

Available reports, both national and international, refer to a specific disease, most often to RA, PSA and SLE. The international literature does not provide the results of studies on the diet and quality of life of rheumatic patients in general. Therefore the results of this study cannot be compared to the results of studies by other authors.

The results of the study on obesity and overweight in the study group are convergent with the data of the Central Statistical Office for the Polish population of adults. In 2009 the prevalence of overweight in Polish women was estimated as $29.4 \%$ and obesity as $15.2 \%$. In men this percentage was $44 \%$ and $16.6 \%$ respectively [15]. The results of this study indicate that obesity is present in $24 \%$ of female patients and overweight in $28 \%$. In men the respective figures are $18 \%$ and $38 \%$. However, it should be noted that the results were based on declarations of the respondents, so they may vary slightly from the actual value.

According to the results of a study by Borges' team carried out in a group of 170 women aged from 18 to 60 diagnosed with SLE, as many as $91.8 \%$ of patients were classified as well-nourished. Only $6.5 \%$ of patients were assessed as moderately malnourished and 1.8\% as seriously malnourished. According to BMI, malnutrition was determined in $1.2 \%$ of patients; the remaining weight categories were the following: normal (healthy weight) $-35.9 \%$ of patients; overweight $-35.3 \%$; and obesity $-27.7 \%$ [16]. Patients reported eating only $72.8 \%$ of estimated energy needs (food intake was assessed by $24-h$ recall and a semi-quantitative food frequency questionnaire). The majority (73.5\%) of patients eat products that meet $90 \%$ of the energy requirement, and $9.6 \%$ of patients eat products of energy value that exceeds the requirements (110\%). Over $92 \%$ of patients use dietary calcium supplements as well as iron supplements (36.7\%) and vitamin $B_{12}(52.3 \%)$ [16]. The Klack 
team, based on a meta-analysis, concluded that the proper diet in the treatment of SLE is oriented towards reducing the risk of cardiovascular diseases and lowering the indices of the inflammatory process. Systemic lupus erythematosus patients receive recommendations for a diet with moderate quantities of protein, rich in mono- and polyunsaturated fatty acids. In the case of diet supplementation, the supply of vitamin D, calcium and selenium is recommended [17]. It is worth bearing in mind that the correct diet and lifestyle determine the correct supply of calcium and vitamin $\mathrm{D}_{3}$ [18]. On the other hand, it is recommended to reduce the intake of zinc and sodium supplements, because there is a risk that it may intensify the symptoms of the disease. A zinc-restricted diet causes an increase in the serum levels of corticosteroids, which can contribute to control of SLE. In order to increase the quality of life of SLE patients, the authors also recommend a diet rich in dietary fibre, vitamin D, taurine, and vitamins A, E, B and C [17]. Thumboo and Strand in a systematic review quote the results of studies indicating a significant relation between a diet low in cholesterol and improvement of the quality of life of patients diagnosed with SLE (randomized study, with a control group). The improvement of the quality of life observed in the study group was from 15 to $17 \%$ $(p=0.05)$ [19].

The results of a multicentre Swedish study carried out in 2010 in a group of 1333 patients diagnosed with rheumatoid arthritis indicated that most of the patients (40.4\%) had normal BMI. In the same study, 39.3\% of patients were overweight or obese (15.8\%). Only $4.4 \%$ of RA patients were underweight. The average value of the $\mathrm{HAQ}$ index for all weight categories was 0.6 (except persons with obesity, i.e. BMI $>30 \mathrm{~kg} / \mathrm{m}^{2}$, where $\mathrm{HAQ}$ was on average 0.7) [20]. A similar study was carried out in Poland (in Poznan) in a group of 52 women (average age 56 years) diagnosed with RA. In the study group normal weight was observed in $38 \%$ of women, overweight in $29 \%$ and obesity in $33 \%$. Increased supply of energy from fats - fatty acids in particular - was observed in the diet as well as an incorrect proportion of omega-6/omega-3 fatty acids. Low intake of folic acid and vitamin D was observed, covering respectively $68 \%$ and $29 \%$ of recommended values, as well as potassium, calcium and magnesium. On the other hand, excessive intake of phosphorus and sodium was noted. As many as $49.5 \%$ of patients in the study group had considerable disease activity [21].

The results of a controlled experimental study carried out in a group of RA patients in Finland by Hanninen indicated the beneficial influence of a vegan diet on the quality of life of RA patients [22]. In the experimental group (that followed a vegan diet) shorter time of morning stiffness of joints was observed ( $p=0.001)$ as well as a lower pain level on the VAS scale $(0.38 ; p=0.003)$ in relation to the control group. It is assumed that supplements of fish oil can also have a good influence on the alleviation of RA symptoms through slowing down the inflammatory processes [23]. A similar relation can be found in anti-TNF- $\alpha$ (tumor necrosis factor $\alpha$ ) therapy. The results of a study carried out in a group of 50 RA patients indicated considerable improvement of the HAQ index in the patients who followed this therapy in comparison to the control group. The initial HAQ index was on average 1.83, whereas after 12 weeks of therapy it had decreased to 1.41 ( $p$ < 0.001) [24]. Sköldstam presented similar results - he performed an experiment in which 26 RA patients followed a Mediterranean diet for 12 weeks (with a control group of 25 patients). In the study group a statistically significant reduction of the HAQ index was observed (average value at the beginning of the study -0.7 , after 12 weeks $-0.6 ; p=0.012$ ) [25]. It is worth mentioning that Gordon presented different results [26]. In an experimental study carried out in a group of 22 RA patients who followed a low-calorie diet, no difference in the value of the HAQ index was observed before and after the experiment (i.e. after 48 weeks of diet with low fat quantities and rich in fibre, vegetables and fruit; $p=0.558$ ). The results of the present study also indicate no difference in HAQ index in relation to the diet in the group of patients suffering from inflammatory diseases (RA, PSA, AS, SLE).

The results of the study carried out by Crilly et al. in a group of 114 RA patients in the UK showed that women (constituting $82 \%$ of the study group) more often included fruit and vegetables in everyday diet (women - 69\%, men - 14\%). Similarly, higher intake of alcohol was observed in the group of women (women - 31\%, men - 16\%) [27]. In contrast to the above-mentioned results, the results of the present study indicate that a vegetable-fruit diet, a meat-free diet or a milk-free diet is followed by a small percentage of patients. In the Crilly study no statistically significant difference in BMI value was observed in the studied groups: the average value of the index in the group of women was 26.8 and in the group of men it was 27.2 [27]. Similarly, in the present study no difference in $\mathrm{BMI}$ range was observed between the group of women and men. It should be however underlined that in contrast to the quoted results of the study carried out in British patients, over $50 \%$ of patients were overweight or obese. Crilly et al. found that in the group of women and men moderate disability, defined using the HAQ index, was observed (95\% Cl: 0.04-0.40; $p=0.02$ ). The average value of the $\mathrm{HAQ}$ index was higher in the group of women (1.1) than in the group of men (0.8) [27]. The results of the present 
study indicate a low disability level among the patients (the average value of HAQ was 0.71).

The results of a study carried out in a group of 126 patients suffering from psoriatic arthritis indicated that the minimum disease activity was often observed in the group of patients who followed a low-calorie diet, compared to the patients who did not follow any diet (OR: 1.85; $95 \% \mathrm{Cl}: 1.019-3.345, p=0.043)$. Over $58 \%$ of patients following a low-calorie diet that lasted 6 months lost weight of more than $5 \%$ of the total body weight. In the group of patients who lost less than $5 \%$, the HAQ index value was $1.29 \pm 0.79 ; p=0.004$, whereas in the group of patients who lost more than $5 \%$ the HAQ index value was $0.53 \pm 0.67$ [28]. The results of a Brazilian study carried out in a group of 34 men from 18 to 60 years old, diagnosed with psoriatic arthritis, indicated that $48 \%$ of patients were overweight and $24 \%$ were obese $(27 \%$ of patients had normal BMI). The index of fat tissue exceeding the regular level (> 25\%) was identified in $60 \%$ of the studied patients. The average intake of carbohydrates in the study group was $42.8 \pm 12.53 \%$, proteins -20.1 $\pm 5.78 \%$, fats $-35.4 \pm 9.6 \%$. Low supply of fibre, vegetables, fruit, vitamins A, B, C, D, selenium and magnesium was observed. On the other hand, high supply of fats, cholesterol and fatty acids was noted. The research showed that inappropriate diet has a considerable influence on the increased risk of chronic diseases related to obesity as well as the deterioration of the quality of life related to the intensification of the disease symptoms [29].

The results of the present study show that in $27 \%$ of patients the diagnosis of rheumatic diseases was followed by a change in diet. This means that even though there is strong awareness of the role of diet in the course of the disease, only a few patients undertake actions to improve their health status through proper diet and body weight control. Understanding the causes of this phenomenon requires further studies.

\section{Conclusions}

1. More than half of patients suffering from rheumatic diseases are overweight or obese, which corresponds to the body weight profile of the population of Poland.

2. Most patients diagnosed with rheumatic diseases do not follow any special diet.

3. In spite of the frequent use of dietary supplements, the patients do not consult a doctor or a dietician about it.

4. The type of diet and BMI value do not differ depending on the level of disability.

The authors declare no conflict of interest.

Financing of the work - the statutory program of the Institute of Rheumatology (S/24).

\section{References}

1. Głuszko P, Filipowicz-Sosnowska A, Tłustochowicz W. Reumatoidalne zapalenie stawów. Reumatologia 2012; 50: 83-90.

2. Scott DL, Wolfe F, Huizinga TW. Rheumatoid arthritis. Lancet 2010; 376: 1094-1108.

3. Cross M, Smith E, Hoy D, et al. The global burden of rheumatoid arthritis: estimates from the Global Burden of Disease 2010 study. Ann Rheum Dis 2014; 73: 1323-1330.

4. Stanisławska-Biernat E, Świerkot J, Tłustochowicz W. Spondyloartropatie. Reumatologia 2012; 50: 93-102.

5. Dean LE, Jones GT, MacDonald AG, et al. Global prevalence of ankylosing spondylitis. Rheumatology (Oxford) 2014; 53 : 650-657.

6. Gabriel SE, Michaud K. Epidemiological studies in incidence, prevalence, mortality, and comorbidity of the rheumatic diseases. Arthritis Res Ther 2009; 11: 229.

7. Majdan M. Toczeń rumieniowaty układowy. Reumatologia 2012; 50: 103-110.

8. Feldman CH, Hiraki LT, Liu J, et al. Epidemiology and sociodemographics of systemic lupus erythematosus and lupus nephritis among U.S. Adults with Medicaid Coverage, 20002004. Arthritis Rheum 2013; 65: 753-763.

9. Leszczyński P, Majdan M, Kucharz EK, et al. Characteristics of Polish patients with systemic lupus erythematosus obtained from the SESAME registry. Activity of the disease, degree of impairment, and availability of social care. Reumatologia 2013; 51: 332-341.

10. Klimiuk PA, Kuryliszyn-Moskal A. Choroba zwyrodnieniowa stawów. Reumatologia 2012; 50: 162-165.

11. Kleinewietfeld M, Manzel A, Titze J, et al. Sodium chloride drives autoimmune disease by the induction of pathogenic Th17 cells. Nature 2013; 496: 518-522.

12. Silman AJ, Pearson JE. Epidemiology and genetics of rheumatoid arthritis. Arthritis Res 2002; 4: 265-272.

13. Cassar-Pullicino VN. The spine in rheumatological disorders. Imaging 1999; 11: 4-118.

14. Tobón GJ, Youinou P, Saraux A. The environment, geo-epidemiology, and autoimmune disease: Rheumatoid arthritis. J Autoimmun 2010; 35: 10-14.

15. Koehne N, Lednicki B, Piekarzewska M, et al. Stan zdrowia ludności Polski w 2009 roku. Główny Urząd Statystyczny, Warszawa 2011.

16. Borges MC, dos Santos Fde M, Telles RW, et al. Nutritional status and food intake in patients with systemic lupus erythematosus. Nutrition 2012; 28: 1098-1103.

17. Klack K, Bonfa E, Borba Neto EF. Diet and nutritional aspects in systemic lupus erythematosus. Rev Bras Reumatol 2012; 52: 384-408.

18. Grygiel-Górniak B, Pawlak-Buś K, Leszczyński P. Sposób żywienia zapewniający optymalną podaż wapnia i witaminy D3. Prz Menopauzalny 2012; 6: 501-505.

19. Thumboo J, Strand V. Health-related quality of life in patients with systemic lupus erythematosus: an update. Ann Acad Med Singapore 2007; 36: 115-122.

20. Ajeganova S, Andersson ML, Hafström I; BARFOT Study Group. Association of obesity with worse disease severity in rheumatoid arthritis as well as with comorbidities: a long-term followup from disease onset. Arthritis Care Res (Hoboken) 2013; 65: 78-87. 
21. Nowak A, Zep W, Straburzyńska-Lupa A, et al. Ocena wartości odżywczej racji pokarmowych kobiet z reumatoidalnym zapaleniem stawów. Reumatologia 2012; 50: 487-492.

22. Hänninen, Kaartinen K, Rauma AL, et al. Antioxidants in vegan diet and rheumatic disorders. Toxicology 2000; 155: 45-53.

23. Rennie KL, Hughes J, Lang R, Jebb SA. Nutritional management of rheumatoid arthritis: a review of the evidence. J Hum Nutr Dietet 2003; 16: 97-109.

24. Metsios GS, Stavropoulos-Kalinoglou A, Douglas KM, et al. Blockade of tumour necrosis factor-a in rheumatoid arthritis: effects on components of rheumatoid cachexia. Rheumatology 2007; 46: 1824-1827.

25. Sköldstam L, Hagfors L, Johansson G. An experimental study of a Mediterranean diet intervention for patients with rheumatoid arthritis. Ann Rheum Dis 2003; 62: 208-214.

26. Gordon MM, Thomson EA, Madhok R, Capell HA. Can intervention modify adverse lifestyle variables in a rheumatoid population? Results of a pilot study. Ann Rheum Dis 2002; 61: 66-69.

27. Crilly MA, Kumar V, Clark HJ, et al. Arterial stiffness and cumulative inflammatory burden in rheumatoid arthritis: a dose-response relationship independent of established cardiovascular risk factors. Rheumatology 2009; 48: 1606-1612.

28. Di Minno MN, Peluso R, lervolino S, et al. Weight loss and achievement of minimal disease activity in patients with psoriatic arthritis starting treatment with tumour necrosis factor $\alpha$ blockers. Ann Rheum Dis 2014; 73: 1157-1162.

29. Solis MY, de Melo NS, Macedo ME, et al. Nutritional status and food intake of patients with systemic psoriasis and psoriatic arthritis associated. Einstein 2012; 10: 44-52. 